\title{
A novel approach to neoplastic ambient topology: application of CW-complexing to junction vertexes of cancerous cells
}

\author{
Reza Sanaye $^{1}$ and Babak Daneshfard ${ }^{1,2,3 *}$ \\ ${ }^{1}$ Essence of Parsiyan Wisdom Institute, Phytopharmaceutical Technology and Traditional Medicine Incubator, Shiraz University of MedicalSciences, Shiraz, Iran \\ ${ }^{2}$ Research Center for Traditional Medicine and History of Medicine, Shiraz University of Medical Sciences, Shiraz, Iran \\ ${ }^{3}$ Department of Traditional Persian Medicine, School of Medicine, Shiraz University of Medical Sciences, Shiraz, Iran
}

The systematics of any probable downsizing within the borderlines of neoplastic tissue growth is dependent upon manipulable differentiable functions either in the realm of complex numbers or kept rigorously inside the non-engineering mathematics [1]. Implicit within this statement is the proposition that sub-segments of small-size tumors are $\mathrm{CW}$-complex mappable.

A reasonable performance as far as the cleavage of organic corresponding systematic are concerned has its origin -in our work-in the counterbalanced downsizing upon the engineering of neoplastic tissues mostly by means of differentiable functions. The specifics of higher-echelon functional presentation in addition to some of its details comprise partial mapping of segments of the manipulable cleaving-border into coordination systems with the accompanied differential equations $[2,3]$. In order to make more rapid evaluation of preclinical/clinical tests' parameters, especially when it comes to modulable nanometric characteristics, we have embarked upon quantitatively statistisizing neoplasm detection by means of bringing together differentiable manifolds (according to the implicit function theorem) and local coordinates.

This is actually carried out where the emerging field of bioprinting could be aided through computer-simulated cytometric topology both short term and long term. As and when orthogonality becomes the ruling order for probable simulation algorithms within the abovementioned context [preferably: micro-ambience], differential manifolds are provided whereby the group-theoretic background material on neoplastic products are translated into their geometric/ topological counterparts. Not only the exterior but also the interior spacing of cellular framework may well be tangented upon if the components of any radially spherical metric in applied topology are also to be taken into consideration. This spells that we have actually managed to make application of $\mathrm{CW}$-complexing to tissue topology [just as Hausdorf to homeomorphic correspondence] when it has been necessary to turn In-Silico and In-Vitro into In-Vivo internuclear "charged" bi-cells, tri-cells, and hexa-cells [4]. Even if the number of sides did not go from five to six, again there would be calculable fractal applications in which the topology of say, any likely tumor, could be approximated by means of change of forces exerted upon the adjacency vertex of (at least) three neighboring cells.

Two specific conditions are of considerable significance in our mathematical-topologic simulation of neoplastics in various forms, volumes, and perimeters: the first would be cleavage mapping functional structures; and the second: induced biophysical force catastrophic collapse near the borderline between the tumor compartment and its non-neoplastic surrounding area.

\section{References}

1. Bizzarri M, Giuliani A, Cucina A, D’Anselmi F, Soto AM, et al. (2011) Fractal analysis in a systems biology approach to cancer. Semin Cancer Biol 21: 175-182. [Crossref]

2. Gray RS, Cheung KJ, Ewald AJ (2010) Cellular mechanisms regulating epithelial morphogenesis and cancer invasion. Curr Opin Cell Biol 22: 640-650. [Crossref]

3. Kim DR, Oettinger MA (1998) Functional analysis of coordinated cleavage in V(D)J recombination. Mol Cell Biol 18: 4679-4688. [Crossref]

4. Godoy P, Hewitt NJ, Albrecht U, Andersen ME, Ansari N, et al. (2013) Recent advances in $2 \mathrm{D}$ and $3 \mathrm{D}$ in vitro systems using primary hepatocytes, alternative hepatocyte sources and non-parenchymal liver cells and their use in investigating mechanisms of hepatotoxicity, cell signaling and ADME. Arch Toxicol 87: 1315-1530. [Crossref]
Copyright: (C2017 Sanaye R. This is an open-access article distributed under the terms of the Creative Commons Attribution License, which permits unrestricted use, distribution, and reproduction in any medium, provided the original author and source are credited.
Correspondence to: Babak Daneshfard $\mathrm{MD}, \mathrm{PhDc}$ in Traditional Persian Medicine; Imam Hossein square, School of Medicine, Shiraz University of Medical Sciences, Shiraz, Iran; Tel: (+98)713-2345145; E-mail: babakdaneshfard@gmail.com

Key words: neoplasm, topology, CW-complexing, cytometry

Received: March 28, 2017; Accepted: April 23, 2017; Published: April 26, 2017 